\title{
DADAÍSMO E SURREALISMO: UMA EXPERIÊNCIA NO CINEMA
}

Antonio Ruzza*

Resumo: Dadaísmo e Surrealismo são duas correntes que revolucionaram a concepção de arte e cultura nas primeiras décadas do século XX, apresentando uma nova visão do mundo, inclusive por meio de manifestos literários e de envolvimento em atividades políticas. Os seus mais significativos representantes (Duchamp, Dalí, Ernst) são mais conhecidos na área das artes visuais. Entretanto, as duas correntes deram uma importante contribuição no campo da literatura, do teatro, da fotografia e do cinema, merecendo a atenção de filósofos, em particular, Benjamin. O cinema é o destaque deste artigo, por meio de uma abordagem filosófica.

Palavras-chave: dadaísmo, surrealismo, cinema, arte, revolução.

\begin{abstract}
Dadaism and Surrealism are two currents that revolutionized the culture and art conception in the first decades of 20th century, showing a new world vision, even through literacy manifests and political activities commitment. Its most significant representatives (Duchamp, Dalí and Ernst) are more known in the visual art field. However, these two currents left an important contribution on the fields of literature, theater, photography and cinema, catching the attention of philosophers, in particular, Benjamin. The cinema field is the focus of this article through a philosophical approach.
\end{abstract}

Keywords: Dadaism, Surrealism, cinema, art, revolution.

\footnotetext{
Graduado em Engenharia pelo Politécnico de Torino (Itália) e em Filosofia pela USJT. Pós-graduado em "Docência para o ensino superior" pelo UNIFAI. Mestre em Filosofia (Epistemologia da Política e do Direito) pela USJT. Doutorando em Filosofia pela PUC. Docente de Filosofia no UNIFAI e na UNI-ÍTALO. Organizou vários grupos de estudo pelo UNIFAI. Publicou Rousseau e a moralidade republicana no Contrato Social (2010) e Em nome das luzes: um desafio à religião (2012), ambas pela Annablume. Publicou o artigo A solução para o problema do absurdo em Albert Camus no livro Deus entre a Filosofia e a Teologia Contemporânea, de 2014, editado pela Appris
} 


\section{Introdução}

Dadaísmo e Surrealismo são dois movimentos das primeiras décadas do século XX, que influenciaram vários aspectos do campo artístico e cultural na Europa, no turbilhão das novas ideias e ações que se desenvolveram neste continente e, em particular na França, a mãe de muitas inovações e revoluções. Eles apresentaram um componente altamente crítico e revolucionário com relação aos valores artísticos e culturais vigentes. Marcaram época, junto ao Cubismo, Expressionismo e Futurismo.

Iniciaremos este trabalho destacando alguns pontos que caracterizam os dois movimentos, que apresentam realizações importantes e mais conhecidas no campo da pintura e literatura. Depois discutiremos um aspecto talvez menos conhecido: o cinema.

\section{Dadaísmo}

O movimento dadá ${ }^{34}$ surgiu oficialmente em 1916, por iniciativa de Tristan Tzara, ${ }^{35}$ em um café de Zurique, cidade que, por estar em um país neutro, havia se convertido em refúgio para políticos e artistas que não queriam envolver-se na primeira guerra mundial.

O dadaísmo não é propriamente um movimento de recusa de uma escola anterior específica, mas se propõe a questionar o conceito de arte, aliás, a destruir todos os sistemas e códigos estabelecidos no mundo da arte. Trata-se de um movimento de rebeldia. Afirma a absoluta rejeição de todo e qualquer tipo de tradição ou esquema anterior, quer libertar a produção artística de qualquer respeito pelo passado ou de qualquer finalidade estética. É contra a beleza eterna, contra as leis da lógica, contra a eternidade dos princípios, contra a imobilidade do pensamento e contra o universal. Valoriza a mudança, a espontaneidade, a liberdade da pessoa, o imediato, o aleatório, a contradição.

Não se sabe ao certo a origem do termo dadaísmo, mas existem várias versões: o falar confuso de uma criança, um brinquedo, um passatempo ocioso dos aristocratas ingleses. Podemos destacar que se trata, voluntariamente, de um termo sem sentido. O movimento nasceu na Suíça e teve a sua maior influência na Alemanha.

${ }^{35}$ Nascido na Romênia em 1896, emigrou para Zurique e, depois, Paris, entrando em contato com vários intelectuais: André Breton (diretor da revista Literature), Philippe Soupault, Louis Aragon. No círculo de Zurique entraram Jean Arp, Marcel Janko, Hans Richter e Richard Huelsenbeck, entre outros. O dadaísmo foi difundido graças ao Manifesto Dadaísta de 1918 e à revista Dadá. As suas ideias chegaram a New York, Berlin e sobretudo Paris. Sucessivamente, Tzara se aproximou do Surrealismo, que tentou conciliar com o marxismo. Fiel a esta ideia, entrou no Partido Comunista Francês e lutou na Espanha contra o franquismo e, na Resistência francesa, contra os nazistas. Morreu em 1963. 
No campo da literatura, poesia e linguagem, o dadaísmo se caracteriza contra o tradicionalismo, pela agressividade verbalizada, a desordem das palavras, a incoerência, a recusa da lógica e do raciocínio, a contradição. Faz uso da falta de sentido da linguagem; as palavras são dispostas conforme surgem no pensamento. Não importa o significado, mas a sonoridade. No Manifesto de Tzara, encontramos frases do tipo: "Eu escrevo um manifesto e não quero nada, eu digo, portanto, certas coisas e sou por princípio contra os manifestos, como sou também contra os princípios." Ou: "Que cada homem grite: há um grande trabalho destrutivo, negativo, a executar. Varrer, limpar. A propriedade do indivíduo se afirma após o estado de loucura, de loucura agressiva, completa, de um mundo abandonado entre as mãos dos bandidos que rasgam e destroem os séculos." Ou: "o verdadeiro dadá é contra o dadaísmo".

No campo das artes visuais (a pintura, em particular), o movimento defende o caos perante a ordem e a imperfeição frente à perfeição. Afirma a antiarte de protesto, do escândalo, do choque, da provocação, com o auxílio dos meios de expressão oníricos, sarcásticos e satíricos. Baseia-se no absurdo, nas coisas carentes de valor. Quer chocar o público. A arte deve evitar as amarras da razão e ser apenas o resultado de um automatismo psíquico, selecionando e combinando elementos por acaso, valorizando o instinto e o subconsciente. Nas palavras de Marcel Duchamp, uma obra de arte pode ser um objeto comum, retirado do seu contexto ordinário e colocado em uma galeria de arte.

A fotografia foi também campo da experimentação inovadora (assim como o cinema, do qual trataremos), sendo o norte-americano Man Ray o seu representante mais conhecido. ${ }^{36}$

Walter Benjamin dedicou algumas páginas ao dadaísmo. Observando que uma tarefa da arte consiste em gerar uma demanda que só pode ser satisfeita mais tarde (por isso é correto falar de vanguarda), ele afirma que...

\footnotetext{
"o dadaísmo tentou produzir através da pintura (ou da literatura) os efeitos que o público procura hoje no cinema(...) O comportamento social provocado pelo dadaísmo foi o escândalo. $\mathrm{Na}$ realidade, as manifestações dadaístas asseguravam uma distração intensa ... Com isso, favoreceu a demanda pelo cinema, cujo valor de distração é fundamentalmente de ordem tátil." ${ }^{37}$
}

\footnotetext{
${ }^{36}$ Fundador com Duchamp do grupo dadá novayorquino, operou também no campo da pintura, atividade que considerava bem diferente da fotografia: "Pinto o que não pode ser fotografado, algo surgido da imaginação, ou um sonho, ou um impulso do subconsciente. Fotografo as coisas que não quero pintar, coisas que já existem". Trabalhou na França. Como cineasta, produziu um filme surrealista, L'Étoile de Mer (1928), com o auxílio de uma técnica chamada solarização, pela qual inverte parcialmente os tons da fotografia. No filme, atrás de uma porta com vidro está acontecendo algo, mas por causa do vidro opaco, o espectador não sabe exatamente o quê. Será um convite a refletir como o conhecimento do mundo é dificil ou impossível?

${ }^{37}$ Benjamin, W. A obra de arte na era da reprodutibilidade técnica, p. 192-194. O filósofo alemão opõe a distração ao recolhimento, que é mais apropriado para uma galeria de arte frequentada por um público mais culto. O cinema quebrou este esquema, fazendo com que um filme de Chaplin distraia mais que um quadro.
} 
Os dadaístas estabelecem também uma forma de viver baseada na liberdade absoluta, tanto que politicamente defendem ideias anarquistas, comunistas e niilistas. Eles se posicionam contra o capitalismo burguês e a guerra promovida com motivação capitalista.

Por tudo isto, o dadaísmo quer estabelecer-se e realmente se estabelece, como vanguarda. Mas o seu objetivo era unicamente destrutivo, pelo menos na opinião de Breton. Não apresentando nenhum projeto concretamente alternativo, o movimento acabou perdendo força por volta de 1923, e muitos dos seus seguidores aderiram ao Surrealismo, mais construtivo. Mas é inquestionável que ele deixou marcas em movimentos posteriores e tem o seu lugar na História. ${ }^{38}$

\section{Duchamp}

Pode ser considerado o representante mais expressivo do Dadaísmo, mas a sua obra ultrapassa os limites deste movimento. ${ }^{39}$

Graças a ele, objetos do cotidiano passaram a ser considerados como obras de arte: são os chamados "ready-mades", conceito introduzido com o famoso A Fonte (um urinol que causou polêmica quando exibido em Nova York em 1917). "Ready-made" significa confeccionado, pronto: pode ser qualquer objeto feito para consumo popular, mas tratado como objeto de arte por opção do artista, utilizado pela e para a arte. Expressa uma crítica do gosto, anula a distinção belo/feio. Quebra a ideia de unicidade da obra, que pode ser reproduzida graças às modernas técnicas. Nas palavras do filósofo analítico Danto:

Duchamp, sozinho, demonstrou que é inteiramente possível algo ser arte sem ter qualquer relação com o gosto, bom ou ruim. Assim ele pôs um fim naquele período do pensamento e da prática estéticos comprometidos, para usar um dos títulos de David Hume, com o "Padrão do Gosto" (The Standard of Taste). Isso não significa que a era do gosto (goût) tenha sido sucedida pela era do mau gosto (degô̂t). Significa antes que a era do gosto tem sido sucedida pela era do sentido, e a questão central não é se algo é de bom ou mau gosto, mas sim o que significa. É verdade que Duchamp tornou possível usar formas e substâncias que realmente induzem ao repulsivo, que agora passou a ser uma opção."40

\footnotetext{
${ }^{38}$ Um seu possível herdeiro é o letrismo, movimento fundado por outro romeno emigrado na França, Isidore Isou (1925-2007), que se opõe à palavra e à sua significação conhecida, buscando o onomatopaico e o fonético. Acabou atuando também nas artes visuais, com obras experimentais feitas de letras (de forma exclusiva ou misturadas com outras imagens) e para o cinema. Gabriel Pomerand, François Dufrêne, Maurice Lemaître, são alguns representantes, além do eclético Guy Debord. Na década de 50, nos EUA, surgiu um movimento "neodadá", com Robert Rauschenberg, Jasper Johns e Louise Nevelson.

${ }^{39}$ Nascido na França em 1887, iniciou a sua atividade de pintor como fauvista e cubista. Instalado em Paris, fez amizade com Apollinaire e Picabia, se entusiasmou pelo teatro de Roussel (que desenvolveu um novo tipo de linguagem na peça Impressions d'Afrique de 1910). Morou muito tempo nos EUA, onde influenciou a pop art, a beat generation, etc. Morreu em 1968.

${ }^{40}$ Artigo de Danto, Marcel Duchamp e o fim do gosto, in: ARS vol.6 no.12 São Paulo July/Dec. 2008, Consulte http://www.scielo.br/scielo.php?script=sci_arttext\&pid=S1678-53202008000200002. Trata-se de uma resposta a Jean Clair, diretor do Museu Picasso em Paris, que definiu Duchamp o culpado da condição deplorável da arte
} 
No campo da pintura, Duchamp é conhecido por duas obras famosas. ${ }^{41}$ A primeira é " $N u$ descendant un escalier", baseada na decomposição do movimento. Na tela, o artista apresenta uma sobreposição de figuras humanas, ou parecidas com seres humanos, descendo uma escada, sugerindo a ideia de um movimento contínuo, uma violação da concepção tradicional da imagem. Este trabalho de 1912 lhe valeu a ruptura com o movimento cubista, que o acusou de apresentar elementos futuristas, por causa das ideias de movimento, desintegração do espaço, maquinismo.

A segunda obra, uma tentativa mais clara de reinventar a pintura, é "Le grande verre", ou "La mariée mise à nu par ses célibataires, même", iniciada em 1912 e interrompida propositalmente em 1923. É composta de dois grandes painéis de vidro duplo, de $2,70 \mathrm{~m}$ de altura e $1,70 \mathrm{~m}$ de largura. Realizada por meio de várias técnicas, na parte superior há a noiva virgem, na inferior, os solteiros pretendentes (existem outros elementos acessórios que dificultam uma única interpretação ou decodificação da mensagem do $\operatorname{artista}^{42}$ ). Christian Schmitt observa que

En effet grâce à ce nouveau module binaire et antithétique appelé refus/réhabilitation, Duchamp installe définitivement sa suprématie parmi les artistes de l'art contemporain. Le Grand Verre n'est que la consécration la plus visible de ce paradoxe. Ainsi la mariée ellemême qui par son attitude va refuser d'abord l'offre des célibataires pour être finalement acceptée. Selon cette même logique il faut donc toujours passer par un refus pour être accepté. Duchamp nous signifie une autre réalité. ${ }^{43}$

Na avaliação de Cécile Debray, trata-se de

(...) uma criação erótica, geométrica, física, fisiológica e espiritual. Tudo isso e também uma negação da pintura: Duchamp fez uma obra que pudesse reunir todos os registros possíveis, fosse uma projeção geométrica de quarta dimensão, elementos psicológicos, matemáticos, e onde se recria a técnica. ${ }^{44}$

contemporânea.

${ }^{41}$ Outras obras inovadoras são Rodas de Bicicletas e uma Mona Lisa com barba e bigode.

${ }^{42}$ Duchamp deixou centenas de anotações provisórias, antes do início e depois que deixou a obra inacabada. Estão reunidas em várias caixas, entre as quais a mais conhecida é a Caixa Verde. Elas não são explicativas da obra; talvez façam parte dela.

${ }^{43} \mathrm{Em} \mathrm{http://lenouveaucenacle.fr/le-grand-verre-de-marcel-duchamp.} \mathrm{Tradução:} \mathrm{"Realmente,} \mathrm{por} \mathrm{meio} \mathrm{desse} \mathrm{novo} \mathrm{módulo} \mathrm{binário} \mathrm{e} \mathrm{antitético}$ chamado 'recusa/reabilitação', Duchamp instala definitivamente a sua primazia entre os artistas contemporâneos. O Grande Vidro é a consagração mais visível desse paradoxo. Assim, é a esposa que, por meio da atitude de recusar inicialmente a oferta dos solteiros, será finalmente aceita. Segundo esta lógica, precisa sempre passar por uma recusa para depois ser aceito. Duchamp dá significado a uma outra realidade".

${ }^{44} \mathrm{Em} \mathrm{http://oglobo.globo.com/cultura/artes-visuais/marcel-duchamp-visto-em-tracos-cores-para-alem-do-ready-made-14143769.} \mathrm{A} \mathrm{Debray} \mathrm{foi} \mathrm{a}$ curadora da exposição em Paris até Janeiro de 2015 (a obra pertence a um museu de Filadélfia). 
Muito discutida e comentada, com diferentes interpretações, ${ }^{45}$ a obra mereceu um estudo aprofundado de cunho filosófico por parte de Octavio Paz.

O escritor mexicano afirma que Duchamp defende o conceito de olhar não retiniano, o único que traz significações, porque ele nega que a pintura seja uma arte puramente manual e visual, tanto que até o título do quadro é importante. Ele não quer fazer um quadro para agradar aos olhos, que servem só como trampolim para saltar mais longe e ver uma outra realidade. Ele não quer converter a sensação estética em um fim, porque é um meio. A sua pintura é signo, é ideia: ela não tem significado em si, mas permite que lhe seja dado pelo observador. Neste sentido, Duchamp supera o dadaísmo ortodoxo, por ele julgado privado do humor que permitirá desembocar no surrealismo onírico. ${ }^{46}$ A partir da afirmação do artista, de que "o espectador faz o quadro", Paz entende que

(...) o artista nunca tem plena consciência da sua obra: entre as suas intenções e a sua realização, entre o que ele quer dizer e o que a obra diz, há uma diferença. Esta diferença é realmente a obra. Pois bem, o espectador não julga o quadro pelas intenções de seu autor, mas pelo que realmente vê. ${ }^{47}$

É a partir do que o espectador acredita ver ${ }^{48}$ que acontece a recriação da obra, que assim é uma "máquina de significar" posta em movimento pelo observador, obrigado a sair de si e modificar-se, mesmo que momentaneamente, a converter-se em um artista (ou um poeta), a operar a passagem entre o mostrado e o escondido. ${ }^{49}$ Paz conclui que, para Duchamp, a obra não é só uma peça de museu, mas um objeto de criação e recriação. A arte é um meio de liberação, contemplação e conhecimento.

$\mathrm{Na}$ eterna relação epistemológica entre sensibilidade e razão, o comentador Campos observa que:

(...) pôde o delineamento dos problemas artísticos abrir espaço para uma problemática extrartística que apontasse para a consciência (ideia), ou seja, voltar-se antes para o contexto (reflexão) do que para o apelo fenomênico do objeto (percepção). Sob este aspecto, Le grand verre remeteria, como nenhuma outra obra de seu tempo (melhor até que

\footnotetext{
${ }^{45}$ Claudia Duarte trata do assunto no ensaio Olhando o Grande Vidro como interface. Destaca (p. 29) a visão dos católicos (uma elevação espiritual, mesmo sendo Duchamp ateu), psicanalítica (a pretensa personalidade obsessiva do artista, a impossibilidade de se comunicar, o tabu do incesto), surrealista (para Breton, é “uma interpretação mecanicista, cínica, do fenômeno amoroso"; um misto de erotismo, especulação filosófica, competição, lirismo, humor).

${ }^{46}$ Paz, O. Marcel Duchamp ou o castelo da pureza, p. 48-49.

${ }^{47}$ Paz, O. Marcel Duchamp ou o castelo da pureza, p. 60.

${ }^{48} \mathrm{Na}$ mesma linha, Claudia Duarte observa que há um encontro da obra com o espectador, mas não pela imagem (que nada mostra), nem pelo texto (que nada diz). Pelo olhar não retiniano, a primeira atua sobre o segundo e vice-versa, permitindo significações. Entretanto, a relação deve excluir (ou superar) o olhar instantâneo, que se limita à forma. In: Olhando o Grande Vidro como interface, p. 31.

${ }^{49}$ Por esta concepção, para o espectador, tem importância a vida do autor com os dramas pessoais, que determinam as suas intenções em fazer um quadro? Pensemos em Van Gogh ou Munch.
} 
os próprios ready-mades, em função de sua complexidade programada), a alguém que aspirou ser mais um filósofo (ou um especulador) do que um artista propriamente dito. ${ }^{50}$

\section{Surrealismo}

Este movimento (cujo nome foi inspirado por um termo usado por Apollinaire para indicar algo acima da realidade) apresenta mais consistência e duração que o dadaísmo, porque é mais construtivo e busca uma nova concepção de arte e de vida. Surgiu na França ${ }^{51}$ no período entre as duas guerras mundiais. Começou como um movimento literário, ${ }^{52}$ que se baseava na associação livre de ideias e na liberdade da linguagem, como forma a libertar o subconsciente do realismo e do naturalismo, num automatismo psíquico que, de forma espontânea, trouxesse à tona um tipo de imaginação que não fosse limitada pelo racional e pelo experimental, dando a conhecer os processos primários pelos quais o pensamento humano acontece. Estruturado por André Breton, ${ }^{53}$ que publica o Manifesto do Surrealismo em 1924 “contra o império da lógica, o racionalismo absoluto e os limites da experiência", o movimento insere-se num conjunto de novas linguagens e técnicas trazidas para a pintura (chamadas de avant-garde, dentro do termo genérico de “modernismo"), que incluíam o expressionismo, o dadaísmo, o cubismo, o futurismo. ${ }^{54}$ De maneira diferente, todos estes movimentos questionavam a visão tradicional da estética e da função da arte, e queriam intervir ou até transformar o mundo. Aos poucos, o ideário surrealista penetrou nos campos da música, dramaturgia ${ }^{55}$ e cinema. Muitos surrealistas se exercitavam contemporaneamente em vários campos, tendo uma visão totalizante de todas as formas culturais.

Os surrealistas encontram inspiração no pensamento de Freud, que pretende aceder a zonas da mente humana habitualmente bloqueadas pela educação, pela repressão sexual e pelas inibições

\footnotetext{
${ }^{50}$ Campos, J. L. Duchamp e o sentido enviesado, p. 10. O comentador cita o trabalho de Uwe Schneede (René Magritte).

${ }^{51}$ Nas primeiras décadas do século XX, Paris era o paraíso e refúgio de intelectuais e artistas de todo tipo e de toda nacionalidade: de Modigliani a Picasso, Chagall, Gershwin, Antheil, Cole Porter, Strawinski, Hemingway, Beckett, Hammett, Scott Fitzgerald, Wilde, Dos Passos, Eliot, Joyce. Entre as mulheres, Edith Warton, Katherine Mansfield, Gertrude Stein, Alice Toklas, Isadora Duncan. Interessante a este respeito o ensaio de William Wiser, Os anos loucos, Olympio Editora.

${ }^{52}$ Os poetas Louis Aragon, Paul Éluard e Philippe Soupault. Mas Benjamin considera que existem precursores no final do século XIX: Rimbaud e Lautréamont, além do contemporâneo Apollinaire (todos mais ou menos "malditos"). Franco Fortini acrescenta os "rebeldes" da primeira década do século XX: Alfred Jarry (o mestre do dandismo, na linha de Oscar Wilde), Pierre Reverdy e Jacques Vaché.

${ }^{53}$ Nascido em 1896, se aproxima ao mundo literário por meio da revista de Pierre Reverdy. Com a chegada de Tzara a Paris, organiza manifestações dadá com Picabia, mas logo se afasta deste movimento, considerado pessimista e puramente destrutivo. Após o Manifesto, radicaliza as suas posições políticas de esquerda, mas entra (como Éluard) em dissidência com o Partido Comunista, considerado dogmático. Escreve ensaios e poemas, além do romance Nadja, que não tem um desenvolvimento linear, mas consiste em eventos isolados e justapostos, que permitem relacionar o amor surrealista com o amor cortês dos provençais medievais. Nas décadas de 40-50, Breton oscilou entre anarquismo e trotskismo. Morreu em 1966.

${ }^{54}$ Os pintores surrealistas mais conhecidos são Ernst, Masson, Magritte, Miró, Dalí, Tanguy. Confluíram no movimento os dadaístas (Duchamp, Man Ray, Picabia). Também De Chirico e Picasso mantiveram afinidades e influências. O mesmo podemos dizer do casal Frida Kahlo / Diego de Rivera, que misturaram elementos surrealistas ao folclore mexicano.
}

${ }^{55} \mathrm{Na}$ música, citaremos Eric Satie; na dramaturgia, Antonin Artaud (com o teatro da crueldade) e Jean Cocteau. 
sociais. O psicanalista austríaco mostra o desejo como motor das aspirações humanas e o sonho como símbolo de desejos inconscientes e não confessados. O objetivo que Freud procura através da hipnose e estudo dos sonhos, os surrealistas o tentam ao criar imagens surpreendentes, bizarras e chocantes, desprovidas de racionalidade e de lógica, inexistentes no mundo do consciente, distorcidas e ilusórias, justapostas com outras imagens com as quais não existe relação alguma. Propondo-se eliminar o limite entre sonho e vigília (este limite que tanto preocupou Descartes na busca de algo seguro que permitisse construir o edifício do conhecimento), eles valorizam o resgate das emoções, ${ }^{56}$ o jogo desinteressado e automático do pensamento, as sensações fortes, o estado de alucinação, a ausência da lógica e da ordem discursiva - racional, a beleza compulsiva e o amor louco, o conflito erótico, a exaltação da liberdade de criação fora de qualquer esquema padronizado, o impulso humano, a adoção de uma realidade superior maravilhosa (mas não sobrenatural ou mística), o acesso ao subconsciente. Um particular destaque é dado ao humor negro, que tem como alvo os pilares da tradição: igreja, família, Estado.

$\mathrm{Na}$ produção artística, a técnica mais usada é a da montagem. Como exemplos destas características, podemos citar os pintores Dalí e Max Ernst. Num quadro de Dalí (Sonho Causado Pelo Voo de uma Abelha ao Redor de Uma Romã um Segundo Antes de Acordar), temos uma mulher nua deitada, tigres que saem da boca de um peixe, uma romã, um elefante suspenso, um rifle apontado sem que ninguém o segure... Ele usou imagens bizarras e oníricas, e na vida privada assumiu posições extravagantes. O seu quadro mais famoso talvez seja a Persistência da memória, de 1931, com os relógios derretidos, segundo o seu princípio de "paranoia crítica". ${ }^{57}$

Uma das características das obras de $\operatorname{Ernst}^{58}$ são as cores fortes e brilhantes. Em seus quadros (como L'Ange du Foyer ou Le Triomphe du surréalisme, de 1937), ele associa imagens de elementos demoníacos e absurdos com outros eróticos e fabulosos.

O movimento recebeu a adesão ou simpatia de intelectuais comprometidos com a causa política da esquerda, que eram críticos dos valores defendidos pela burguesia (inclusive na estética, pela concepção de arte pela arte). Muitos se assumiram como intelectuais "engagés" e tentaram estabelecer uma ligação entre cultura (incluindo aqui a liberdade de criação artística) e a política revolucionária.

\footnotetext{
${ }^{56}$ Nesta atitude e na crítica geral à sociedade, alguns críticos detectam uma ligação com o romantismo do século anterior. Discordamos desta visão, pois o romantismo se apresenta antimoderno, religioso e saudosista de um passado como aquele do ancien régime.

${ }^{57}$ Salvador Dalí nasceu em 1904 na Catalunha, e foi para Paris em 1924, entrando no grupo surrealista. Afastou-se do grupo na década de 1940, inclusive por motivos políticos, pois abandonou as ideias de esquerda (até denunciou o cineasta Buñuel para as autoridades dos EUA, onde os dois moravam) e passou a apoiar discretamente o regime do ditador espanhol Franco. Faleceu em 1989.

${ }^{58}$ Nascido em 1891 na Alemanha, fundou em Colônia o grupo dadá em 1919. Emigrado na França, se uniu ao grupo de Breton. Os nazistas incluíram as suas obras na "arte degenerada". Após um longo período nos EUA, voltou para Paris, onde faleceu em 1976.
} 
Resumindo, nas palavras do comentador Fortini, três elementos caracterizam o surrealismo: um conjunto de ideias sobre a natureza, as possibilidades e o futuro do homem; um método para investigar certas experiências psicológicas; um complexo de comportamentos práticos, morais e políticos. ${ }^{59} \mathrm{O}$ objetivo geral não seria substituir a realidade, mas unificá-la com o surreal: afinal, um sonho pode ser transcrito somente por quem estiver acordado; a revolta contra a razão deve usar "martelos reais".

Walter Benjamin, em O surrealismo: o último instantâneo da inteligência europeia, observa que não é um simples movimento artístico, e que os seus seguidores desenvolvem um conceito radical de liberdade, e

(...) são os primeiros a liquidar o fossilizado ideal dos moralistas e dos humanistas, porque sabem que a liberdade, que só pode ser adquirida neste mundo com mil sacrifícios, quer ser desfrutada, enquanto dure, em toda a sua plenitude e sem qualquer cálculo pragmático. ${ }^{60}$

No seu entender, o movimento "mobiliza para a revolução as energias da embriaguez", mas este momento não é suficiente, porque é anárquico, de pura provocação e negação, sem a disciplina comunista que transforma a revolta em revolução social, caracterizando um segundo momento. Para superar tal insuficiência, o grupo passa por uma radicalização política, teorizada por Pierre Naville. ${ }^{61}$ Entretanto, para Breton e Benjamin, este segundo momento não elimina (ou melhor, não deveria eliminar) o primeiro, mas o complementa. É o que o filósofo alemão chama de "iluminação profana", que faz encontrar elementos não percebidos no primeiro momento, aquele em que tudo era automático. Sabemos que no "mundo real" isto não aconteceu.

O comentador Gatti explica o conceito de iluminação profana introduzido por Benjamin:

Durante os primeiros anos, a experiência surrealista se caracteriza por transfigurar a realidade cotidiana com o fascínio do misterioso, do desconhecido, do maravilhoso. Nos momentos de embriaguez artística produzidos pela experiência com a escrita automática, ${ }^{62}$ que vence a censura da consciência, e pelas montagens de fragmentos desconexos da realidade, o mundo se revela numa iluminação que dissolve suas contradições entre interior e exterior, entre sonho e vigília, entre individual e coletivo. Como diz Aragon no Camponês de Paris, a realidade é a ausência aparente de contradição. O maravilhoso é a contradição que aparece no real. Mas, diferentemente da iluminação religiosa, a iluminação profana não remete a uma ordem transcendente. Ao contrário, a sobre-realidade - a surrealité - nasce da

\footnotetext{
${ }^{59}$ Fortini, F. O movimento surrealista, p. 10.

${ }^{60}$ Benjamin, W. In: Magia e Técnica, Arte e Politica, volume I, p. 32. Este ensaio é de 1929.

${ }^{61}$ Naville (1903-1993) é autor de La Révolution et les intellectuels, de 1926. Afastou-se do movimento por volta de 1929, divergindo de Breton por motivos políticos (julgava impossível a integração entre surrealismo e comunismo) e filosóficos (entre outros pontos, defendia o materialismo mecânico dos iluministas, condenado por Marx). Desenvolveu a teoria do "pessimismo revolucionário" em oposição ao otimismo sobre a vitória previsível e certa do comunismo mundial.

${ }^{62}$ Escrita automática é aquela que produz imagens sem intenção, ao acaso. Num segundo momento, são entendidas como parte de uma surrealité.
} 
crença de que a realidade mais concreta é formada por essa convivência de opostos. Os objetos oníricos são o domínio da realidade mais concreta, em oposição àquela apontada pelo pensamento lógico ou abstrato. O fantástico, o além, o sonho, a sobrevida, o paraíso, o inferno, a poesia, tantas palavras para significar o concreto. ${ }^{63}$

Contra Naville, Breton insiste que o irracional pode conviver com o racional, sem descartálo; o sonho pode ser mantido mesmo na vigília; o maravilhoso pode realizar-se na revolução social, numa espécie de marxismo libertário. ${ }^{64}$

Esta expressão é usada por Michael Lowy, autor de A estrela da manhã: surrealismo $e$ marxismo, no qual fala também de "encantamento revolucionário" de Benjamin com Breton, e de "marxismo gótico" comum aos dois: um materialismo histórico sensível à dimensão mágica das culturas do passado. Lowy explica também que a embriaguez surrealista definida por Benjamin é diferente dos êxtases religiosos ou daquela provocada pelas drogas; é materialista e antropológica. Isso evitaria a instrumentalização da arte por parte da política. ${ }^{65}$

Num Segundo Manifesto de 1930, escrito também para defender a adesão, sem reservas, do movimento ao comunismo (conforme a evolução intuída por Benjamin, com resultados históricos não propriamente satisfatórios), Breton critica os que buscam transformar o desconhecido em conhecido, e os que acreditam que são possíveis só as coisas que "existem". Afirma também que "nós combatemos sob todas as formas a indiferença poética, a distração artística, a pesquisa erudita, a especulação pura, e não queremos ter nada em comum com os economizadores de espírito."

Após a segunda guerra mundial, o movimento surrealista continuou existindo oficialmente, apesar de ter perdido a força da novidade, fato que justificou a tentativa de dissolução proposta por Jean Schuster. A causa foi uma maior aceitação do existencialismo no mundo intelectual francês de esquerda. Filósofos desta tendência (Sartre) ou próximos (Camus) se debruçaram sobre o surrealismo, com avaliação negativa. ${ }^{66}$

Sartre, em Qu'est-ce que c'est la littérature?, de 1948, define o surrealismo como uma corrente que, querendo eliminar a distinção entre consciente e inconsciente, acaba destruindo a subjetividade, que consiste em saber que pensamentos e sensações vêm de nós mesmos; e também a objetividade, porque produz objetos imaginários. Na crítica radical à burguesia, os surrealistas

\footnotetext{
${ }^{63}$ Gatti, L. Walter Benjamin e o Surrealismo: Escrita e Iluminação profana. In: Artefilosofia, Ouro Preto, n. 6, p. 82.

${ }^{64}$ Este modelo uniria anarquismo e comunismo. Uma união impossível, devida à incompatibilidade entre o centralismo controlador do segundo, e o desejo de livre pensamento do primeiro, insoferente ao controle e à subordinação cultural. Isso foi bem demonstrado pelos trágicos fatos durante a guerra civil espanhola. Quase todos os surrealistas acabaram saindo do Partido Comunista na década de 1930, inclusive Breton, Éluard, Aragon e Naville, preferindo a dissidência trotskista ou outras escolhas individuais.

${ }^{65}$ Este objetivo está no Manifesto para uma arte revolucionária independente, escrito por Breton com a colaboração de Trotsky, por ocasião do encontro dos dois no México em 1938.

${ }^{66}$ Extraído de Fortini, O movimento surrealista, p. 226-234.
} 
tornaram-se os parasitas dela, numa atitude falsamente revolucionária, puramente destrutiva, distante do proletariado. Um fracasso: quando a negação é total, ela não sabe intervir na realidade que se quer destruir.

No Homme revolté, de 1951, Camus considera o surrealismo ser um componente do niilismo. Os seus traços são a não-culpabilidade absoluta do homem, que pode cometer qualquer coisa, do crime ao suicídio, seguindo o seu desejo. Para isso, era necessário subverter a sociedade e o uso da razão, fazer uma revolução qualquer, sem objetivo declarado. O paradoxo é ter aderido ao comunismo apesar daquilo que mais detestam nele: o planejamento racional e a ordem. Tentando unir as duas correntes, somente Naville chegou à única conclusão coerente: o pessimismo, que é um traço do niilismo, quando o espírito não consegue fixar-se nem nesta vida, nem no além.

No pós-guerra, uma liderança importante foi Vincent Bounoure, que em La civilisation surréaliste, afirma:

Qualquer exteriorização surrealista é, ao longo de meio século de existência, testemunha de oposição, ou pelo menos para retomar a fórmula de Charles Fourier, declaração de afastamento absoluto. A história do Surrealismo é a história deste protesto. ${ }^{67}$

Trata-se da recusa do mundo industrial-capitalista e da sua lógica racional-positivista. Para Lowy, o surrealismo não é eterno, nem historicamente acabado; é atual, porque não é uma simples vanguarda artística destinada a terminar; ele é destinado a inovar. ${ }^{68}$ Ele é o que será!

Neste sentido, uma atitude surrealista poderá continuar a ter sentido porque

(...) a despolitização cada vez mais acentuadas das massas, estendida mesmo a um país como a França de tradicional vivacidade política; as formidáveis novas armas do conformismo que a técnica moderna pôs à disposição das burocracias para criar e satisfazer as necessidades culturais da massa, mantêm viva e renovam de decénio em decénio a exigência da revolta permanente. ${ }^{69}$

E talvez o seu grande mérito histórico é ter posto em destaque uma parte do homem injustamente condenada ou esquecida: desejo, eros, sonho, delírio.

Entre outros movimentos que partiram de uma concepção surrealista e tentaram superá-la ou completá-la, gostaríamos de lembrar a chamada Internacional Situacionista (1957-1972) animada

\footnotetext{
${ }^{67}$ Lowy, M. A estrela da manhã: surrealismo e marxismo, p. 93.

${ }^{68}$ Lowy, M. A estrela da manhã: surrealismo e marxismo, p. 103-104.

${ }^{69}$ Fortini, F. O movimento surrealista, p. 55.
} 
por Guy Debord, cineasta e escritor. ${ }^{70}$ Ela assume a tarefa de "superar" a arte, abolindo a noção de arte como uma atividade especializada e separada, e transformando-a naquilo que seria parte da construção da vida cotidiana. Para os situacionistas, a arte ou é revolucionária ou não é nada.

Agora, passaremos a comentar brevemente a presença e a influência dos dois movimentos no cinema.

\section{Cinema dadaísta}

O melhor exemplo desta atividade é Anémic Cinéma, filme experimental de Duchamp sob o pseudônimo de Rose Sélavy (o seu alter ego feminino), feito em 1926, em colaboração com Man Ray. No filme, não há trama; somente uma série de imagens hipnóticas, concêntricas ou em espiral, discos rotativos em cortes rápidos e abstratos, que evoluem para formas tridimensionais, criando uma falsa ilusão da realidade.

Ao mesmo tempo, aparecem no filme as seguintes frases, também em espiral sobre os discos:

1. Bains de gros thé pour grains de beauté sans trop de Bengué. 2. L'enfant qui téte est un souffleur de chair chaude et n'aime pas le chou-fleur de serre chaude. 3. Si je te donne un sou me donneras tu une paire de ciseaux? 4. On demande des moustiques domestiques (demi-stock) pour la cure d'azote sur la Côte d'Azur. 5. Inceste ou passion de famille, à coups trop tirés. 6. Esquivons les ecchymoses des esquimaux aux mots exquis. 7. Avez vous deja mis la moëlle de l'épée dans le poële de l'aimée? 8. Parmi nos articles de quincaillerie paresseuse, nous recommandons le robinet qui s'arrête de couler quand on ne l'écoute pas. 9. L'aspirant habite Javel et moi j'avais l'habite en spirale. ${ }^{71}$

Esta mistura de imagens e palavras é consequência da importância que Duchamp dá à linguagem e à sua função transgressora, marcada pela provocação e pela ironia. A uma palavra ele quer dar um valor semântico arbitrário, que separa o termo do seu conteúdo expressivo, com humor e malícia. Cria trocadilhos que quebram a lógica do discurso, o significado objetivo, por meio de enunciados aparentemente ilógicos e sem sentido. A linguagem perde a referência com o real, em total oposição à fillosofia analítica. Assim, a palavra "anémic" não revela somente o caráter fraco da

\footnotetext{
${ }^{70}$ Debord (1931-1994) é autor de A Sociedade do espetáculo (1967), obra muito popular durante a revolta estudantil do "Maio francês" de 1968.

${ }^{71}$ Extraído de: http://pt.wikipedia.org/wiki/Cinema_An\%C3\%AAmico. Tradução: 1. Banho de chá forte, para grãos de beleza, sem muita Bengué (Bengué ou BenGay era um analgésico inventado pelo médico francês Jules Bengué). 2. A criança cuja cabeça é um soprador de cadeiras quente e não ama couve-flor de estufa quente. 3. Se eu te der um centavo, tu me darás um par de tesouras?" 4. Exigimos mosquitos domésticos (meia estoque) para cura de azoto, na Côte d'Azur. 5. Incesto ou paixão de família, a golpes fortes. 6. Esquivamo-nos de contusões dos esquimós com requintadas palavras. 7. Você já foi a medula da espada na panela do amado? 8. Entre nossas ferramentas preguiçosas, recomendamos a torneira que para de fluir quando não se ouve. 9. O aspirante vive na água sanitária e eu tive que habitar a espiral.
} 
nova forma artística, mas é um seu anagrama. O que interessa é a subversão dos sentidos e não a comunicação (que poderia ser impossível). O cinema se apresenta útil a este objetivo. ${ }^{72}$

O objetivo de Duchamp é testar as percepções humanas através dessas espirais e frases. Ele nos faz perceber coisas que não perceberíamos normalmente, ${ }^{73}$ em sua tentativa de negar a visão da arte como contemplação retinária. A alternância de "disco-figura" e "disco-palavra", com velocidade aumentada, nos deixa intrigados ou encantados com o que (não) significam as imagens e frases que aparecem. E com uma pergunta: qual o sentido de tudo isso? Filosoficamente, podemos dizer que é uma tentativa de mostrar a dificuldade de penetrar na realidade? Mas é possível pensar que a projeção em duas dimensões esconde uma terceira dimensão, que pode tornar-se visível quando os discos rodam. A ilusão de sentido transforma-se na realidade de sentido.

Concluindo, Anémic Cinéma contém elementos dadaístas (rejeição das regras lógicas, falta de acontecimentos, desejo de surpreender e talvez de confundir) e surrealistas (desvelamento de uma realidade escondida).

\section{Cinema surrealista}

A valorização da imagem, unida à técnica cubista de colagem, faz do cinema (que usa montagem e corte) um meio eficaz para os surrealistas difundir as suas ideias, como mostrar um sonho através da imagem visual e sonora, ou reproduzir o curso direto do pensamento. A chamada sétima arte, mostrando o sonho e o impossível, podia muito bem escapar das amarras do realismo.

Já foi comentado que os trabalhos pioneiros de Duchamp, Man Ray e René Clair são uma ponte entre dadaísmo e surrealismo. Apesar de que muitos críticos se perguntam se existe uma definição de filme completamente surrealista, temos elementos típicos que justificam esta definição: artifícios narrativos desconcertantes, simbologia freudiana, exploração de desejos reprimidos e uso constante de uma ironia subversiva e humor negro, para confundir e provocar os espectadores. $\mathrm{O}$ que vemos na tela, inquestionavelmente algo captado da realidade, não tem um significado conhecido e definitivo. Os objetos e os personagens não são estranhos, dada a nossa experiência com eles, mas a câmera e a montagem criam um significado dialético ou ideológico para aquele objeto ou para aquela situação: no mínimo, dois significados, um metafórico e um formal. É

\footnotetext{
${ }^{72}$ Artigo de Márcia Arbex: Anémic Cinéma, uma experiência do avesso da linguagem. A autora destaca a influência de Roussel e Brisset. Infelizmente, a tradução em português faz perder a força dos trocadilhos.

${ }^{73}$ Seria uma surrealidade. Por causa disso, alguns críticos consideram que este filme é uma ponte entre dadaísmo e surrealismo. Nesta mesma linha deve ser considerado o filme de 1924, Entr'acte, de René Clair (que depois teve uma bem-sucedida carreira no cinema falado), auxiliado por Francis Picabia: é um conjunto de imagens que não precisam ter uma história com sentido, mas compõem uma espécie de balé visual.
} 
impossível entender o filme como uma "história no tempo"; ele é uma experiência condenada à dúvida, a múltiplas interpretações.

Artaud foi o primeiro surrealista a escrever para o cinema um argumento completo, realizado pela diretora Germaine Dulac ${ }^{74}$ em La coquille et le clergyman, de 1928. O tema é um amor louco entre uma moça e um padre, dividido entre o desejo ardente e o senso de culpa: é claro o objetivo de chocar a opinião pública e de fazer largo uso do simbólico, pois a concha seria o órgão sexual feminino.

Mas o mais conhecido representante desta fase inicial é Luis Buñuel. Em parceira com Salvador Dalí, ele dirige Un chien andalou (1929) e L'âge d'or (1930), trabalhos que não têm uma história linear, mas saltos no tempo e dificuldade de definir o que é sonho e o que não é. São trabalhos feitos com poucos recursos, sem compromissos com o convencionalismo e o mercado (que não era tão importante como hoje). O roteiro não deve permitir explicações racionais ou psicológicas.

O primeiro filme inicia com uma cena chocante: uma navalha corta o olho (a janela freudiana da alma, que permite o contato imediato com o mundo) de uma mulher. A mensagem parece clara: o sujeito precisa, mesmo à custa de um grande sofrimento, livrar-se do instrumento que lhe faz ver uma realidade, para poder ver uma "surrealidade" que nunca viu ou não quis ver. $\mathrm{Na}$ sequência, um homem, no auge de seus impulsos sexuais, é impedido de realizá-los. Ele se abaixa e agarra duas cordas, e quando ele as puxa, percebe o peso daquilo. Quando ele finalmente consegue puxá-las, vê um piano, um burro morto e dois padres enforcados. Também vemos nas costas do homem reprimido duas tábuas que lembram as dos dez mandamentos. Enfim, o homem impossibilitado de concretizar seus desejos sexuais, seus instintos, carrega nas costas todas as regras e valores da sociedade, todo o mal-estar da civilização, como disse Freud. A oposição entre razão e instinto, entre liberdade e censura, encontra espaço em Un chien andalou, ao lado da hipocrisia dos religiosos, como em todas as futuras obras de Buñuel. Para satisfazer seus desejos mais íntimos e incontroláveis, muitas vezes de origem sexual, o homem tem de se livrar das amarras da sociedade para que consiga olhar a realidade com outros olhos.

L'âge d'or parece mais provocatório, e o título é sarcástico, porque é mostrado um mundo de crimes e de violência. Um casal passa por um conjunto de privações. O filme foi acusado de blasfêmia por identificar Jesus com uma personagem de Sade.

\footnotetext{
${ }^{74}$ Dulac, talvez a primeira diretora europeia (1882-1942), havia antes realizado cerca de vinte curtas metragens mais convencionais, sendo o mais conhecido La souriante Madame Beudet, de 1922.
} 
Na década de 1930, após a ruptura com Dalí, o cineasta espanhol se afasta do movimento, passando por uma segunda fase nos EUA e México, na qual trata de temas sociais (Nazarin, Los Olvidados, da década de 1950); e por uma terceira fase na sua volta à França. ${ }^{75}$ Mas a influência do ideário surrealista continua muito presente na sua obra.

Após a segunda guerra mundial, não podemos falar de cinema puramente surrealista, mas da presença de fortes elementos entre cineastas de tendências mais variadas. Afinal, o sonho, o inconsciente, o pesadelo, as proibições, os amores impossíveis, a falta de lógica nos pensamentos e nas ações, a não distinção entre sonho e vigília, os desejos mais indizíveis, os finais surpreendentes ou inexplicáveis, são partes essenciais da realidade humana, que o cinema sabe explorar muito bem. $^{76}$

\section{Considerações finais}

Dadaísmo e, sobretudo, surrealismo são movimentos bem característicos do clima agitado e até revolucionário que existia na Europa nas primeiras décadas do século XX. Estruturados em movimentos, buscaram dar uma nova interpretação da arte, legando-a a outros aspectos da atividade humana: cultural (literatura, pintura, teatro, cinema) e política, com o objetivo de superar a dicotomia entre arte e vida e apresentar uma nova visão do mundo, que não fosse apenas do "real". A dificuldade da empresa explica porque, sobretudo os surrealistas, passaram por mudanças e rupturas entre os seus adeptos. Mas é inquestionável a sua importância como momento específico da história da arte e do pensamento humano.

No caso do cinema, ${ }^{77}$ a contribuição pode perecer menos importante (talvez porque menos conhecida) do que na pintura e literatura ${ }^{78}$ na realidade, ela é mais indireta, porque é pontual entre cineastas que são considerados clássicos.

\footnotetext{
${ }^{75} \mathrm{Na}$ década de 1960/70 temos Viridiana, O anjo exterminador, Bela da tarde, A via Láctea, Tristana, O discreto charme da burguesia, O fantasma da liberdade, Este obscuro objeto do desejo, nos quais trata, sempre de modo polêmico, da complexidade das relações humanas, dos seus aspectos irracionais e de seus enlaces desconcertantes. Buñuel nasceu em 1900 no Aragão e mudou-se em 1925 para Paris. Faleceu no México em 1983.

${ }^{76}$ Podemos citar Hitchcock (Quando fala o coração, com a colaboração de Dalí; Os pássaros), Bergman (O sétimo selo), Fellini (Julieta dos espíritos; Satyricon), Cronenberg (A hora da zona morta), Lynch (Veludo azul), Scorsese (A ilha do medo).

${ }^{77}$ No Brasil, somente em 1954 Paulo Emílio Salles Gomes organiza a primeira Mostra do Cinema de São Paulo, na qual são projetados os filmes antes citados de Clair, Man Ray, Dulac, Buñuel. Foi dado espaço a filmes brasileiros pouco conhecidos que apresentam traços surrealistas, como Limite, de Mário Peixoto; Canga bruta, de Humberto Mauro; e O canto do mar, de Alberto Cavalcanti.

${ }^{78}$ No Brasil, vários artistas e intelectuais, pela relação com os surrealistas franceses (inclusive Benjamin Péret, que aqui viveu vários anos), realizaram obras de claros traços surrealistas e criaram grupos, mostras e revistas: na década de 1930 e 1940, o grupo antropofágico, Mário Pedrosa, Patrícia Galvão (a Pagú), Ismael Nery, Maria Martins, Cicero Dias, Flávio de Carvalho; a partir da década de 1950, Murilo Mendes, Claudio Willer, Clarice Lispector, e outros, além de Michael Lowy, que mora na França. Em 1967, o grupo surrealista brasileiro, liderado por Sergio Lima, organizou em São Paulo uma Exposição Internacional do Surrealismo intitulada A mão mágica e o andrógino primordial.
} 


\section{Referências Bibliográficas}

BENJAMIN, W. Magia e Técnica, Arte e Política. Brasília: Brasiliense Editora, 2010.

DUARTE, C. Marcel Duchamp: olhando o Grande Vidro como interface. São Paulo; N. Imagem, 2010.

FORTINI, F. O movimento surrealista. Lisboa: Editorial Presença, 1965.

LOWY, M. A estrela da manhã: surrealismo e marxismo. Rio de Janeiro: Civilização Brasileira, 2012.

PAZ, O. Marcel Duchamp, ou o castelo da pureza. São Paulo: Perspectiva, 2010. 